\title{
Management and Disposition of Atrial Fibrillation in the Emergency Department: A Systematic Review
}

\author{
Justin L. Vandermolen ${ }^{1}$, Murrium I. Sadaf ${ }^{1}$, Anil K. Gehi ${ }^{1}$ \\ ${ }^{1}$ Division of Cardiology, Department of Medicine, University of North Carolina, Chapel Hill, NC.
}

\begin{abstract}
Introduction: Management of atrial fibrillation (AF) and atrial flutter (AFL) in the emergency department (ED) varies greatly, and there are currently no United States guidelines to guide management with regard to patient disposition after ED treatment. The aim of this systematic review was to evaluate the literature for decision aids to guide disposition of patients with AF/AFLin the ED, and assess potential outcomes associated with different management strategies in the ED.

Methods and Results: A systematic review was done using PubMed (MEDLINE), Cochrane Central Register of Controlled Trials (CENTRAL), and EMBASE, combining the search terms "Atrial Fibrillation", "Atrial Flutter", "Emergency Medicine", "Emergency Service", and "Emergency Treatment". After removal of duplicates, 754 articles were identified. After initial screening of titles and abstracts, 69 full text articles were carefully reviewed and $\mathbf{3 4}$ articles were ultimately included in the study based on inclusion and exclusion criteria. The articles were grouped into four main categories: decision aids and outcome predictors, electrical cardioversion-based protocols, antiarrhythmic-based protocols, and general management protocols.

Conclusion: This systematic review is the first study to our knowledge to evaluate the optimal management of symptomatic AF/AFLin the ED with a direct impact on ED disposition. There are several viable management strategies that can result in safe discharge from the ED in the right patient population, and decision aids can be utilized to guide selection of appropriate patients for discharge.
\end{abstract}

\section{Introduction}

Atrial fibrillation $(\mathrm{AF})$ is the most common dysrhythmia worldwide, with an estimated prevalence of 2.7 to 6.1 million in the United States (US) alone ${ }^{[1]}$. The risk for developing AF increases with advancing age, and the US prevalence is predicted to increase to as high as 12.1 million by the year 2030 as the elderly population continues to grow ${ }^{[2]}$. Along with the increased burden of disease, emergency department (ED) visits for symptomatic AF have continued to rise over the last 25 years, almost doubling from 1993 to $2004^{[3]}$. Despite a fairly stable relative rate of hospitalizations, the absolute number of hospitalizations for $\mathrm{AF}$ continues to climb as ED visits become more frequent ${ }^{[3]}$. National incremental healthcare costs of $\mathrm{AF}$ in the US are estimated to range from $\$ 6$ to $\$ 26$ billion, and a large portion of these expenses are related to inpatient hospitalization ${ }^{[4]}$. By preventing unnecessary hospital admissions for $\mathrm{AF}$, it could be surmised that both healthcare costs and unwanted complications associated with hospitalization could be significantly reduced. The most recent American Heart Association/American College of Cardiology/Heart and Rhythm Society guidelines for management of $\mathrm{AF}$ do not specifically address management in the $\mathrm{ED}^{[5]}$. However, recent guidelines from the Canadian Cardiovascular

\section{Key Words}

Atrial Fibrillation, Atrial Flutter, Emergency Medicine, Emergency Service, Emergency Treatment

Corresponding Author

Anil K. Gehi,

Associate Professor of Medicine Cardiac Electrophysiology Division of Cardiology CB 7075, 160 Dental Circle 6025 Burnett-Womack Bldg. Chapel Hill, NC 27599-7075
Society do provide recommendations for ED management of AF, noting that there is increasing evidence that many patients with $\mathrm{AF}$ can be safely managed in the ED and discharged to home, without necessitating hospitalization ${ }^{[6]}$. The aim of our study was to search the existing literature for management strategies and decision aids for triaging ED patients with $\mathrm{AF}$, specifically with a plan for selecting patients appropriate for outpatient management.

\section{Methods}

Study Population

We performed a literature search on October 12, 2016 using PubMed (MEDLINE), Cochrane Central Register of Controlled Trials (CENTRAL), and EMBASE. The searches combined the terms "Atrial Fibrillation", "Atrial Flutter", "Emergency Medicine", "Emergency Service", and "Emergency Treatment". Additional relevant articles that were identified as references for the articles found during the primary search were also included in the review process. Articles published in English were accepted for this review, and non-English language articles were excluded at the title/abstract screening stage. Randomized controlled trials, non-randomized controlled trials, prospective and retrospective cohort studies, casecontrol studies, and case series were included. Cross-sectional studies, case reports, editorials, letters, comments, abstracts and poster presentations, guidelines, meta-analyses, and review articles were excluded.

Manuscripts selected for this review included: 1) ED management strategies for symptomatic AF or atrial flutter (AFL) directed toward 
ED discharge, 2) a focus on the efficacy and/or safety of triaging or management protocols to assist with disposition of patients with $\mathrm{AF} / \mathrm{AFLin}$ the ED, and 3) evaluation of short term outcomes $(<3$ months) of patients with a primary diagnosis of AF/AFLwho were discharged from the ED. Articles that focused on the management of $\mathrm{AF} / \mathrm{AFL}$ in the $\mathrm{ED}$ but without a direct impact on disposition were excluded. Articles that explored past predictors of hospital admission for AF/AFL without relating to patient outcomes were excluded. Articles that only evaluated outcomes more than 3 months after ED discharge were excluded, as we felt short term outcomes were more likely to be related to ED management and discharge. Additionally, articles that primarily focused on acute and long-term anticoagulationfor stroke prophylaxis were excluded.

After the initial database search and removal of duplicates, articles were screened and included or excluded based on title and abstract information. The articles that were included after this initial screening stage were then analyzed using full-text review, and included or excluded based on the previously mentioned inclusion/ exclusion criteria. The entire screening process was performed by two independent reviewers (JV, MS)utilizing the Covidence web-based software platform, and conflicts were resolved by consensus with the assistance of a third independent reviewer (AG). The methodology for this systematic review is summarized in [Figure 1].

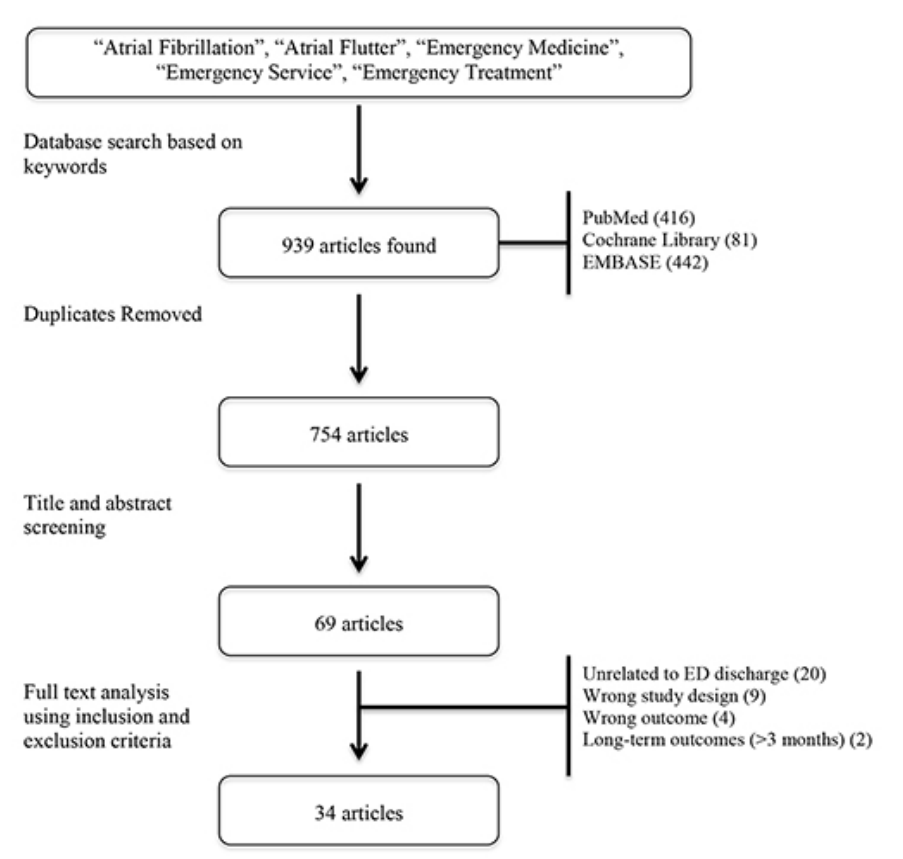

\section{Figure 1: Systematic Review Process}

Data extraction was performed individually by the two primary independent reviewers for the studies that were included after full text analysis. Relevant factors from each study were assessed for the final qualitative analysis, including study design, patient population, follow-up period, and interventions and outcomes.

\section{Results}

We identified a total of 939 articles (416 from PubMed, 81 from Cochrane Library, and 442 from EMBASE). Duplicates were excluded, resulting in 754 remaining articles. These articles were carefully screened based on information gathered from the titles and abstracts, leaving 69 articles to be analyzed by full text review. Twenty articles were excluded because although they discussed the management of AF/AFLin the ED, they did not specifically address patient disposition from the ED. Nine articles used one of the study designsthat we chose to exclude and 4 had irrelevant patient outcomes for our topic of interest. Finally, 2 articles were excluded because their primary focus was on long-term patient outcomes. This left 34 remaining studies to be included in our review. There were 4 randomized controlled trials, 10 prospective cohort studies, 12 retrospective cohort studies, 6 prospective case series, and 2 retrospective case series. Because our inclusion criteria allowed for some variety in the content of our articles, we grouped the articles into 4 separate categories: decision aids and outcome predictors, electrical cardioversion-based protocols, antiarrhythmic-based protocols, and general management protocols.

\section{Decision Aids and Outcome Predictors}

Seven of the articles focused specifically on how to determine which patients with AF/AFLcan be safely discharged from the ED by analyzing short term outcomes and creating novel prediction models and decision aids [Table 1$]^{[7-13]}$. The retrospective analysis done by Mulcahy et al reviewed the charts of all patients who presented to the ED with new-onset AF from 1987 to 1992, all of whom were subsequently admitted to the inpatient ward per hospital policy at that time ${ }^{[7]}$. Based on the overall hospital courses and interventions required while inpatient, they found that about onethird of these patients did not merit inpatient hospitalization, and $98 \%$ of those that did require inpatient care were easily identified while in the ED. RED-AF, a prediction model created by Barrett et al, assigned points for 12 clinical variables in $\mathrm{ED}$ patients with $\mathrm{AF} /$ $\mathrm{AFL}$ and predicted the risk of an adverse event at 30 days based on total points ${ }^{[8]}$. The initial model had modest predictive discrimination and was later prospectively validated with similar performance as the original cohort ${ }^{[11]}$. The biggest predictors of increased risk for shortterm adverse events were increased age, inadequate ED rate control, dyspnea, smoking, and home beta-blocker use ${ }^{[8]}$. The AFFORD prediction model for 30-day adverse events was also created by Barrett et al, a few years after RED-AF, and assigned points to 17 different variables for risk stratification ${ }^{[12]}$. Atzema et al created both a complex as well as a pragmatic clinical decision instrument for risk-stratification, both of which performed well for predicting 30 -day all cause mortality ${ }^{[13]}$. Compared with the complexity of the previous models, the pragmatic model (TrOPs-BAC) includes only 6 variables (positive troponin, other acute ED diagnosis, pulmonary disease, bleeding risk, age 75 years or older, and congestive heart failure) and can easily be memorized for quick reference. Atzema et al performed a large retrospective cohort study to look for factors associated with death within 90 days of an ED discharge after a visit for AF/AFL, and found that having no follow-up care was associated with the highest risk for short-term death (hazard ratio [HR] 2.27) [9]. This group also explored predictors for repeat $\mathrm{ED}$ visits for $\mathrm{AF} /$ AFL within 2 weeks of an ED discharge, and found that follow-up with a cardiologist or internist was associated with the lowest hazard for repeat visits (HR 0.61) ${ }^{[10]}$.

\section{Electrical Cardioversion-Based Protocols}

Seven of the articles primarily analyzed the safety and efficiency 
Table 1:

Author/Yea

Mulcahy et
al $1996^{7}$

Barrett et al

$2011^{8}$

Atzema et al $2013^{\circ}$

Atzema et al $2013^{10}$

Retrospective cohort study

12,772 cohort study

Retrospective $\quad 12,772$ cohort study

No. of
Patients

Inclusion

Criteria

Retrospective 229

cohort study

ED patients with new diagnosis $\mathrm{AF}$

Intervention

Determination of medical justification of hospitalization for $A F$

ED patients with AF/AFL

ED patients $>65$ years old with primary diagnosis AF/AFL

ED patients $>65$ years old with primary diagnosis AF/AFL

Barrett et al 2015 $\quad$ Prospective 497 cohort study

ED patients with stable AF/AFL

Prospective validation of RED-AF prediction mode

Derivation and internal validation 30-day adverse events of RED-AF prediction model

Discharge home from the ED

Discharge home from the ED

Return ED visit within 14 days

Rate of medically justified admissions

ED or hospital complications

(2)

O-day adverse events

ED patients with Derivation and internal validation 30-day adverse events of AFFORD clinical decision aid cohort study $\quad 497$ stable AF/AFL

ED patients with primary diagnosis AF 30-day all cause mortality
Derivation and validation of complex and pragmatic decision models for disposition of ED patients with AF

\section{Results}

$1 / 3$ of admitted AF patients did not merit hospitalization

$98 \%$ of medically justified admissions could be identified in the ED

RED-AF had modest predictive discrimination for the primary outcome (c-statistic of 0.67 )

$3 \%$ death rate within 90 -days Significantly increased hazard of death for patients with no outpatient follow-up

$9 \%$ of patients had a return ED visit Patients with specialist outpatient follow-up less likely to return

Patients with only family practice outpatient follow-up, high acuity triage score, and history of $\mathrm{CHF}$ more likely to return

RED-AF performed similar to the original derivation cohort (c-statistic of 0.65 ) Clinically relevant threshold score had $96 \%$ sensitivity, 19\% specificity, PPV 27\%, NPV 93\%

AFFORD performed moderately well for predicting risk of short-term adverse outcomes (c-statistic of 0.7)

Both models were highly predictive of the outcome (c-statistic 0.87 and 0.81 for complex and pragmatic model, respectively)

$\mathrm{AF}=$ atrial fibrillation, $\mathrm{AFL}=$ atrial flutter, $\mathrm{CHF}=$ congestive heart failure, $\mathrm{ED}=$ emergency department, $\mathrm{NPV}=$ negative predictive value, $\mathrm{PPV}=$ positive predictive value

of direct-current cardioversion (DCCV) as a means to successfully discharge patients home from the ED [Table 2] ${ }^{[14-20]}$. Conversion rates for DCCV were as high as $97 \%$ in the prospective cohort study by Jacoby et al, and no lower than $78 \%$, which was the rate observed by Dankner et a ${ }^{[15,17]}$. In each of these studies, almost all of the patients who converted to normal sinus rhythm (NSR) were discharged home from the ED. Several of the studies noted a small number of minor ED complications with DCCV, primarily related to procedural sedation ${ }^{[14,16,18,19,20]}$. No major adverse events were observed within 3 months of discharge after ED DCCV in any of the included studies.

\begin{tabular}{|c|c|c|c|c|c|c|}
\hline Table 2: & Electrical ca & oversion & & & & \\
\hline Author/Year & $\begin{array}{l}\text { Study } \\
\text { Design }\end{array}$ & $\begin{array}{l}\text { No. of } \\
\text { Patients }\end{array}$ & $\begin{array}{l}\text { Inclusion } \\
\text { Criteria }\end{array}$ & Intervention & $\begin{array}{l}\text { Key Outcome } \\
\text { Measures }\end{array}$ & Results \\
\hline Burton et al $2004^{14}$ & $\begin{array}{l}\text { Retrospective } \\
\text { cohort study }\end{array}$ & 388 & ED patients with stable AF & $\begin{array}{l}\text { Elective DCCV } \\
\text { Elective CC } \\
\text { Rate control only }\end{array}$ & $\begin{array}{l}\text { ED disposition } \\
\text { Conversion to NSR } \\
\text { ED and 1-week adverse events }\end{array}$ & $\begin{array}{l}86 \% \text { of all patients discharged home } \\
86 \% \text { conversation rate with DCCV } \\
28 \text { ED DCCV complications }\end{array}$ \\
\hline Jacoby et al $2005^{15}$ & $\begin{array}{l}\text { Historically } \\
\text { controlled } \\
\text { prospective } \\
\text { cohort study }\end{array}$ & 60 & $\begin{array}{l}\text { ED patients with primary } \\
\text { diagnosis stable AF/AFL } \\
\text { AF duration }<48 \text { hours }\end{array}$ & $\begin{array}{l}\text { Elective DCCV } \\
\text { Historical controls with rate } \\
\text { control only and hospital } \\
\text { admission }\end{array}$ & $\begin{array}{l}\text { ED disposition } \\
\text { Conversion to NSR } \\
\text { Post-discharge adverse events }\end{array}$ & $\begin{array}{l}80 \% \text { of DCCV patients discharged home } \\
97 \% \text { conversion rate with DCCV } \\
\text { No adverse events noted with telephone } \\
\text { follow-up for DCCV patients }\end{array}$ \\
\hline Lo et al $2006^{16}$ & $\begin{array}{l}\text { Prospective } \\
\text { case series }\end{array}$ & 33 & $\begin{array}{l}\text { ED patients with stable AF } \\
A F \text { duration }<48 \text { hours }\end{array}$ & Elective DCcV & $\begin{array}{l}\text { ED disposition Conversion to } \\
\text { NSR ED and 3-month adverse } \\
\text { events }\end{array}$ & $\begin{array}{l}79 \% \text { of all patients discharged home } 91 \% \\
\text { conversion rate with DCCV No major adverse } \\
\text { events at } 3 \text { months }\end{array}$ \\
\hline Dankner et al $2009^{17}$ & $\begin{array}{l}\text { Retrospective } \\
\text { cohort study }\end{array}$ & 374 & $\begin{array}{l}\text { ED patients with stable } \\
\text { AF AF duration }<48 \\
\text { hours or }>48 \text { hours with } \\
\text { therapeutic INR }\end{array}$ & $\begin{array}{l}\text { Elective DCCV Elective CC } \\
\text { Rate control only }\end{array}$ & $\begin{array}{l}\text { ED disposition } \\
\text { Conversion to NSR } \\
1 \text { and 2-week adverse events }\end{array}$ & $\begin{array}{l}53 \% \text { of DCCV patients discharged home } \\
78 \% \text { conversion rate with DCCV } \\
\text { No definite treatment-related adverse events } \\
\text { with DCCV }\end{array}$ \\
\hline $\begin{array}{l}\text { Scheuermeyer et al } \\
2010^{18}\end{array}$ & $\begin{array}{l}\text { Retrospective } \\
\text { case series }\end{array}$ & 400 & $\begin{array}{l}\text { ED patients with primary } \\
\text { diagnosis stable AF/ } \\
\text { AFL AF/AFLduration }<48 \\
\text { hours or }>48 \text { hours with } \\
\text { therapeutic INR }\end{array}$ & Elective DCCV & $\begin{array}{l}\text { ED disposition } \\
\text { Conversion to NSR } \\
\text { ED and 30-day adverse events }\end{array}$ & $\begin{array}{l}97 \% \text { of patients discharged to home } \\
97 \% \text { conversion rate with DCCV } \\
\text { No major } 30 \text {-day adverse events } \\
4.3 \% \text { rate of minor procedural complications }\end{array}$ \\
\hline $\begin{array}{l}\text { Scheuermeyer et al } \\
2011^{19}\end{array}$ & $\begin{array}{l}\text { Retrospective } \\
\text { cohort study }\end{array}$ & 122 & $\begin{array}{l}\text { ED patients with primary } \\
\text { diagnosis stable AFL }\end{array}$ & $\begin{array}{l}\text { Elective DCCV } \\
\text { Elective CC } \\
\text { Spontaneous cardioversion } \\
\text { Rate control only No rate or } \\
\text { rhythm control }\end{array}$ & $\begin{array}{l}\text { ED disposition } \\
\text { Conversion to NSR } \\
\text { ED adverse events }\end{array}$ & $\begin{array}{l}93 \% \text { of DCCV patients discharged home } \\
91 \% \text { conversion rate with DCCV patients } \\
2 \text { DCCV patients had minor procedural } \\
\text { complications }\end{array}$ \\
\hline Cristoni et al $2011^{20}$ & $\begin{array}{l}\text { Prospective } \\
\text { cohort study }\end{array}$ & 322 & $\begin{array}{l}\text { ED patients with stable AF } \\
A F \text { duration }<48 \text { hours }\end{array}$ & $\begin{array}{l}\text { ED SOU management } \\
\text { (DCCV vs. CC) }\end{array}$ & $\begin{array}{l}\text { ED disposition } \\
\text { Conversion to NSR } \\
\text { Short-term adverse events }\end{array}$ & $\begin{array}{l}94 \% \text { of patients discharged from ED in DCCV } \\
\text { group vs. } 56 \% \text { in CC group } \\
93 \% \text { conversion rate in DCCV group vs. } 51 \% \\
\text { in CC group } \\
\text { No significant difference in short-term adverse } \\
\text { events }\end{array}$ \\
\hline
\end{tabular}

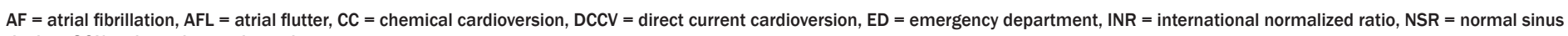
rhythm, SOU = short observation unit 
Table 3:

\section{Author/Year}

nnes et al $1997^{21}$

Randomized controlled trial

156

Ganau et al $1998^{22}$

Ergene et al $1998^{23}$

Prospective

cohort study

50

ED patients with stable

Domanovits et al

$2000^{24}$

Prospective

case series

51

1
AF/AFL AF duration $<48$

Mountantonakis et al $2006^{25}$

Prospective

36

Viktorsdottir et al

$2006^{26}$

Retrospective

46

cohort study

Stiell et al $2007^{27}$

Retrospective $\quad 341$ case series

\section{Hirschl et al $2011^{28}$ \\ Prospective} cohort study

376

\begin{abstract}
ED patients with stable hours
\end{abstract}

Retrospective cohort study

259

cheuer
$2013^{29}$

White et al $2015^{30}$

Historically
controlled
prospective
cohort study

104

ED patients with
primary diagnosis stable
AF/AFL AF/AFLduration $<48$ hours
$\mathrm{AF},<75$ years of age $\mathrm{AF}$

duration $<72$ hours

ED patients with stable hours

ED patients with stable

AF/AFL AF duration $<72$ hours

ED patients with stable AF/AFL AF duration $<7$ hours

ED patients with primary diagnosis stable AF/AFL AF/AFLduration $<48$ hours

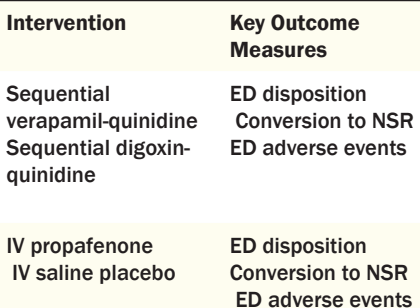

IV flecainide

ED patients with primary $\quad B B C C B$

diagnosis stable AF DCCV for nonresponders

IV ibutilide

PO propafenone

IV ibutilide Rate

control only

IV procainamide

with DCCV for non-

responders

IV ibutilide IV

amiodarone IV

magnesium IV

digoxin IV diltiazem

IV digoxin +

diltiazem

ED adverse events

ED disposition

Conversion to NSR

Predictors for successful

conversion

ED adverse events

ED disposition

Conversion to NSR

ED adverse events

ED disposition Conversion to NSR ED adverse events

ED disposition

Conversion to NSR

ED adverse events

ED disposition Conversion to NSR ED adverse events

ED disposition Conversion to NSR ED adverse events

IV procainamide with DCCV for

non-responders Historical controls

with standard care

ED disposition ED LOS ED and 30-day adverse events

ED disposition Conversion to NSR 30-day adverse events
Results

$63 \%$ of VER-Q and $27 \%$ of DIG-Q discharged home from ED $84 \%$ of VER-Q patients and $45 \%$ of DIG-Q patients successfully converted within 6 hours No significant adverse events

$65 \%$ of propafenone patients and $20 \%$ of placebo patients discharged home from ED

$70 \%$ of propafenone patients and $17.3 \%$ of placebo patients converted within 2 hours

4 patients with minor, transient complications

$78 \%$ of patients discharged home from ED $78 \%$ conversion rate

Higher response rate for symptom onset $<24$ hours

3 patients with severe hypotension responsive to IV fluids

$92 \%$ of all patients discharged home from ED $75 \%$ conversion rate with ibutilide, $100 \%$ conversion rate with ibutilide +/- DCCV No major adverse effects

All patients who converted discharged home from ED 69\% conversion rate No major adverse effects

All patients who converted discharged home from ED $64 \%$ conversion rate in ibutilide group vs. $29 \%$ in rate control group

No adverse effects in ibutilide group

94.4\% discharged home from ED

$50 \%$ conversion rate with procainamide alone, $91 \%$ with procainamide +/- DCCV

$10 \%$ rate of adverse events, transient hypotension most common

All cardioverted and rate controlled patients discharged home from ED

$45 \%$ overall conversion rate; flecainide (95\%) and ibutilide ( $75 \%$ ) had highest success rates $4 \%$ adverse event rate, lowest in digoxin and digoxin + diltiazem group

No significant difference in ED LOS or discharge home from ED for BB vs. CCB ( $78 \%$ and $69 \%$, respectively) No major ED adverse

$93 \%$ of cohort discharged home from ED vs. $40 \%$ of historical controls

$94 \%$ conversion rate for cohort vs. $56 \%$ of historical controls No major adverse events

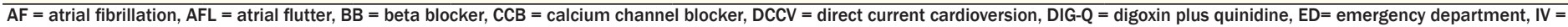

intravenous, LOS = length of stay, NSR=normal sinus rhythm, PO = by mouth, VER-Q= verapamil plus quinidine

Notably, hemodynamic instability was an exclusion criterion for all of these studies, so DCCV was done purely on an elective basis. Additionally, 3 of the 7 studies required the onset of AF/AFL to be less than 48 hours prior to ED presentation for study inclusion ${ }^{[15,16,20]}$. The other 4 studies permitted an earlier onset of symptoms, but the large majority of patients still only had symptoms for 48 hours or less, no fewer than $68 \%$ of the cohort in the AFL study done by Scheuermeyer et al ${ }^{[14,17,18,19]}$.

\section{Antiarrhythmic-Based Protocols}

Ten of the articles dealt with medical management of AF in the $\mathrm{ED}$, either with chemical cardioversion or rate control alone [Table $3]^{[21-30]}$. Chemical cardioversion had varying success rates depending on the pharmacologic agent that was chosen. The combinations of verapamil-quinidine and digoxin-quinidine used by Innes et al resulted in $84 \%$ and $45 \%$ conversion rates to NSR, respectively ${ }^{[21]}$. Intravenous (IV) and oral (PO) propafenone had $70 \%$ and $78 \%$ successful conversion rates, respectively ${ }^{[22,23]}$. The use of IV ibutilide resulted in conversion rates ranging from $64 \%$ to $76 \%[24,25,26,28]$. IV procainamide was used by Stiell et al and White et al with a $50 \%$ and $67 \%$ success rate, respectively ${ }^{[27,30]}$. Hirschl et al compared a variety of different medications, and found that flecainide (95\%) and ibutilide (76\%) had the highest rates of conversion to NSR ${ }^{[28]}$. Similar to the DCCV studies, all of these studies required a recent onset of AF/AFL for study inclusion. Only one of the articles in our study evaluated rate control alone with regard to ED discharge, comparing outcomes of those who received beta-blockers vs. calcium channel blockers, finding no significant differences in discharge rates or short-term adverse events ${ }^{[29]}$.

\section{General Management Protocols}

NThe final category included ten articles, which either explored the efficacies of several different AF/AFL management strategies with the goal of ED discharge, or used specific protocols designed 
to appropriately triage and disposition ED patients with AF/AFL [Table 4 $]^{[31-40]}$. Michael et al and Vinson et al compared several different ED management strategies, with DCCV being the most successful with regard to conversion to $\mathrm{NSR}^{[31,38]}$. However, $97 \%$ and
$89 \%$ of all patients were discharged to home in Michael and Vinson's groups, respectively, including those who only underwent rate control or observation. Vinson et al observed a $29 \%$ rate of spontaneous cardioversion in the ED without any intervention; this rate improved

\begin{tabular}{|c|c|c|c|c|c|c|}
\hline Table 4: & General Man & gement $\mathbf{P}$ & rotocols & & & \\
\hline Author/Year & $\begin{array}{l}\text { Study } \\
\text { Design }\end{array}$ & $\begin{array}{l}\text { No. of } \\
\text { Patients }\end{array}$ & $\begin{array}{l}\text { Inclusion } \\
\text { Criteria }\end{array}$ & Intervention & $\begin{array}{l}\text { Key Outcome } \\
\text { Measures }\end{array}$ & Results \\
\hline Michael et al $1999^{31}$ & $\begin{array}{l}\text { Retrospective } \\
\text { cohort study }\end{array}$ & 289 & $\begin{array}{l}\text { ED patients with primary } \\
\text { diagnosis stable } A F\end{array}$ & $\begin{array}{l}\text { Elective DCCV } \\
\text { Elective CC } \\
\text { SC before or after } \\
\text { treatment } \\
\text { Rate control only }\end{array}$ & $\begin{array}{l}\text { ED disposition } \\
\text { Conversion to NSR } \\
\text { ED and 1-week adverse } \\
\text { events }\end{array}$ & $\begin{array}{l}97 \% \text { of all patients discharged home } \\
89 \% \text { conversion rate for DCCV, } 50 \% \text { for CC, } 15 \% \\
\text { spontaneously converted } \\
\text { No adverse events with DCCV, } 9 \% \text { complication rate with CC }\end{array}$ \\
\hline Koenig et al $2002^{32}$ & $\begin{array}{l}\text { Prospective } \\
\text { case series }\end{array}$ & 67 & $\begin{array}{l}\text { ED patients with stable } \\
\mathrm{AF} \\
\mathrm{AF} \text { duration }<48 \text { hours } \\
\text { Failed ED cardioversion }\end{array}$ & $\begin{array}{l}\text { EDOU management } \\
\text { (rate control, CC, } \\
\text { and/or DCCV) }\end{array}$ & $\begin{array}{l}\text { ED disposition } \\
\text { Conversion to NSR } \\
\text { ED and 1-week adverse } \\
\text { events }\end{array}$ & $\begin{array}{l}81 \% \text { of patients discharged home from ED } \\
82 \% \text { overall conversion rate } \\
\text { No major adverse events }\end{array}$ \\
\hline Kim et al $2002^{33}$ & $\begin{array}{l}\text { Randomized } \\
\text { controlled trial }\end{array}$ & 18 & $\begin{array}{l}\text { ED patients with } \\
\text { primary diagnosis new- } \\
\text { onset, stable } A F,<75 \\
\text { years old }\end{array}$ & $\begin{array}{l}\text { Accelerated ED } \\
\text { pathway } \\
\text { Hospital admission }\end{array}$ & $\begin{array}{l}\text { ED disposition } \\
\text { ED/hospital LOS } \\
\text { ED adverse events }\end{array}$ & $\begin{array}{l}100 \% \text { conversion rate and discharge home from ED for } \\
\text { accelerated pathway } \\
\text { Mean LOS was } 2.1 \text { days for hospital admission vs. }<1 \text { day } \\
\text { for accelerated pathway } \\
\text { No major adverse events }\end{array}$ \\
\hline $\begin{array}{l}\text { Zimetbaum et al } \\
2003^{34}\end{array}$ & $\begin{array}{l}\text { Prospective } \\
\text { cohort study }\end{array}$ & 446 & $\begin{array}{l}\text { ED patients with } \\
\text { primary diagnosis new- } \\
\text { onset, stable AF }\end{array}$ & $\begin{array}{l}\text { ED AF practice } \\
\text { guideline Pre- } \\
\text { intervention } \\
\text { standard care }\end{array}$ & $\begin{array}{l}\text { ED disposition } \\
\text { 30-day return visits and } \\
\text { adverse events }\end{array}$ & $\begin{array}{l}49 \% \text { decrease in probability of hospital admission } \\
\text { No difference in 30-day return visits or hospitalizations } \\
\text { No 30-day strokes or death }\end{array}$ \\
\hline Decker et al $2008^{35}$ & $\begin{array}{l}\text { Randomized } \\
\text { controlled trial }\end{array}$ & 153 & $\begin{array}{l}\text { ED patients with primary } \\
\text { diagnosis stable } \mathrm{AF} \\
\text { AFduration, }<48 \text { hours }\end{array}$ & $\begin{array}{l}\text { EDOU protocol } \\
\text { Hospital admission }\end{array}$ & $\begin{array}{l}\text { ED disposition } \\
\text { Conversion to NSR or rate } \\
\text { control } \\
\text { ED, 30-day, and 6-month } \\
\text { adverse events }\end{array}$ & $\begin{array}{l}85 \% \text { of EDOU discharged home from ED } \\
85 \% \text { conversion rate in EDOU group vs. } 73 \% \text { in hospital } \\
\text { admission group } \\
\text { No significant difference in short term adverse effects }\end{array}$ \\
\hline Stiell et al $2010^{36}$ & $\begin{array}{l}\text { Prospective } \\
\text { case series }\end{array}$ & 660 & $\begin{array}{l}\text { ED patients with } \\
\text { primary diagnosis stable } \\
\text { AF AF/AFL duration, } \\
<48 \text { hours }\end{array}$ & $\begin{array}{l}\text { Ottawa Aggressive } \\
\text { Protocol }\end{array}$ & $\begin{array}{l}\text { ED disposition } \\
\text { Conversion to NSR } \\
\text { ED and 1-week adverse } \\
\text { events }\end{array}$ & $\begin{array}{l}97 \% \text { of all patients discharged home from ED } \\
92 \% \text { successful conversion rate with IV procainamide }+/- \\
\text { DCCV } \\
\text { No major adverse events }\end{array}$ \\
\hline $\begin{array}{l}\text { Scheuermeyer et al } \\
2012^{37}\end{array}$ & $\begin{array}{l}\text { Retrospective } \\
\text { cohort study }\end{array}$ & 927 & $\begin{array}{l}\text { ED patients with primary } \\
\text { diagnosis stable AF }\end{array}$ & $\begin{array}{l}\text { Elective DCCV } \\
\text { Elective CC } \\
\text { SC Rate control } \\
\text { only }\end{array}$ & $\begin{array}{l}\text { ED disposition } \\
\text { Conversion to NSR } \\
\text { ED and 30-day adverse } \\
\text { events }\end{array}$ & $\begin{array}{l}85 \% \text { of patients discharged home } \\
46 \% \text { conversion rate to NSR } \\
3 \% \text { rate of adverse events in ED, } \\
0.8 \% \text { rate of stroke or death at } 30 \text { days }\end{array}$ \\
\hline Elmouchi et al $2014^{39}$ & $\begin{array}{l}\text { Prospective } \\
\text { case series }\end{array}$ & 100 & $\begin{array}{l}\text { AF clinic patients } \\
\text { seen in follow-up after } \\
\text { discharge home from } \\
\text { ED visit for AF }\end{array}$ & $\begin{array}{l}\text { Spectrum Health } \\
\text { AF Protocol with AF } \\
\text { clinic follow-up }\end{array}$ & $\begin{array}{l}\text { 90-day return ED visits } \\
\text { or hospitalization } 90 \text {-day } \\
\text { mortality and TE events }\end{array}$ & $\begin{array}{l}10 \text { AF-related return ED visits, } 3 \text { AF-related hospitalizations } \\
\text { within } 90 \text { days No deaths or TE events at } 90 \text { days }\end{array}$ \\
\hline Ptaszek et al $2016^{40}$ & $\begin{array}{l}\text { Prospective } \\
\text { cohort study }\end{array}$ & 359 & $\begin{array}{l}\text { ED patients with stable } \\
\text { AF }\end{array}$ & $\begin{array}{l}\text { AF treatment } \\
\text { pathway Standard } \\
\text { care }\end{array}$ & $\begin{array}{l}\text { ED disposition Repeat } \\
\text { visits or hospitalization }\end{array}$ & $\begin{array}{l}84 \% \text { of AF pathway patients vs. } 20 \% \text { of controls discharged } \\
\text { home from ED } \\
\text { No significant difference in short-term readmissions }\end{array}$ \\
\hline
\end{tabular}

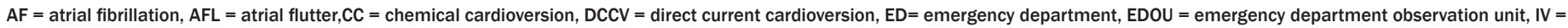
intravenous, $\mathrm{LOS}=$ length of stay, NSR = normal sinus rhythm, SC = spontaneous cardioversion, $\mathrm{TE}=$ thromboembolic

to $69 \%$ within 48 hours of discharge to home ${ }^{[38]}$. Scheuermeyer et al looked at outcomes of ED patients with symptomatic AF and no other underlying medical cause who received a similar variety of interventions, with $85 \%$ of patients discharged home from the ED and a $0.8 \%$ rate of stroke or death at 30 days $^{[37]}$. Koenig et al observed an $81 \%$ discharge rate with no major adverse events after utilization of an ED observation unit for those who did not respond initially to ED management ${ }^{[32]}$. Stiell et al used a case series to evaluate the Ottawa Aggressive Protocol, which consisted of administration of IV procainamide followed by DCCV for those who did not convert to NSR initially, and showed that $97 \%$ of patients were discharged home from the ED without any major adverse events ${ }^{[36]}$. Kim et al and Decker et al both randomized patients to undergo protocols geared toward ED discharge vs. hospital admission, and found no significant difference in short-term adverse events ${ }^{[33,35]}$. Zimetbaum et al and Ptaszek et al compared their AF protocols to standard ED care, and found a $49 \%$ and $80 \%$ decreased probability of hospital admission, respectively, with no significant differences in short-term adverse events or hospitalizations ${ }^{[34,40]}$. Elmouchi et al created the Spectrum Health ED AF protocol, which had different treatment algorithms based on time of AF onset, and required close follow-up in an AF-specific clinic ${ }^{[39]}$. Out of 100 included patients, there were only 10 repeat $\mathrm{ED}$ visits and 3 hospitalizations for $\mathrm{AF}$ within 90 days, with no deaths or thromboembolic events.

\section{Discussion}

To our knowledge, this is the first systematic review to evaluate the optimal management of AF/AFL in the ED, specifically with regard 
to appropriate triaging and disposition. Based on the results of the included articles, there are multiple, varying strategies to approach management as well as risk stratification. Moreover, our review suggests that by using these strategies, most patients can be safely discharged from the ED and managed successfully in the outpatient setting. Based on our review, we concluded three major findings: 1) decision aids and prediction models can be useful for determining ED disposition, 2) electrical cardioversion is more successful than medical management in converting to NSR, and 3) conversion to NSR is not required to allow for safe ED discharge.

Deciding which patients are safe to discharge from the ED and which require inpatient admission is not always straightforward, but one of our primary findings was that using prediction models can be helpful for stratifying patients. The RED-AF and AFFORD clinical tools both had modest predictive discrimination for their outcomes of interest, and the decision instruments created by Atzema et al were highly predictive of 30 -day all cause mortality ${ }^{[8,11,12,13]}$.Unlike many of the articles in this review, these decision aids did not exclude patients with other underlying acute medical conditions requiring hospitalization,which could broaden their applicability.Each of these studies was done at a single academic institution, and further validation in a variety of ED settings would strengthen the case for widespread use of these decision instruments. Regardless of risk stratification, transitions of care are an important aspect of acute AF/ AFL management. Atzema et al demonstrated in 2 different articles that patients without adequate short-term follow-up had worse outcomes, reinforcing that close outpatient follow-up is important to ensure a safe ED discharge ${ }^{[9,10]}$.

Electrical cardioversion was largely very successful in the articles we reviewed and helped with discharge from the ED. Several of the studies in the DCCV group directly compared electrical and chemical cardioversion, and found DCCV to have significantly higher successful conversion rates ${ }^{[14,17,19,20]}$. Although none of the studies in the antiarrhythmic group directly compared chemical cardioversion to DCCV, all of the pharmacologic agents had lower conversion rates than the results seen in the DCCV studies. A few of the chemical cardioversion studies used DCCV as an adjunct therapy for those who did not initially respond to the pharmacologic agents, with subsequent improvement of successful cardioversion ${ }^{[24,27,30]}$. In each study in the DCCV and antiarrhythmic groups, almost all patients who converted to NSR were discharged home from the ED. Importantly, with either DCCV or chemical cardioversion, it was critical to know the exact onset of the AF/AFL episode to ensure that the onset was less than 48 hours duration. In many cases this cannot be reliably determined and would thus warrant a transesophageal echocardiogram. This limits the utility of this strategy in many patients. In addition, in these patients with new onset $\mathrm{AF} / \mathrm{AFL}$, it is possible that many will spontaneously convert without an intervention in the ED, as a large proportion will likely have paroxysmal AF/AFL.

The final group of articles employed a combination of rate control, DCCV, chemical cardioversion, and observation alone, most by using implemented pathways and protocols with the aim of ED discharge when possible. These studies demonstrated a high success rate of
ED discharge, regardless of the type of acute management that was chosen or rhythm status at time of discharge. It is interesting to note that the articles in the general management group demonstrated a similar rate of short-term adverse events to the articles in the $\mathrm{DCCV}$ and chemical cardioversion groups, many of which required patients to convert to NSR in order to be discharged ${ }^{[15,17-18,20,25-30]}$. While conversion to NSR seems desirable, particularly in patients with acute onset of AF/AFL, there is no particular reason that persistence of AF/AFL should preclude ED discharge, provided that rate control is adequate and the patient is otherwise stable and not severely symptomatic. This is supported by the articles that observed reasonably high rates of spontaneous conversion to NSR, as well as the studies mentioned that observed high rates of safe discharges, regardless of ED intervention ${ }^{[31,37,38]}$. Future studies exploring optimal ED management for symptomatic AF/AFL with rate control or observation alone could help elucidate if and when aggressive rhythm control is actually merited.

\section{Limitations}

There are several limitations to consider in this review. We performed a qualitative assessment of a somewhat heterogeneous group of articles based on our study design, and thus did not perform any summative statistical calculations for either population baseline characteristics or outcomes. We did not restrict study inclusion based on individual study quality, which may inherently allow for bias in our overall assessment based on the individual study results. Although many of the studies had relatively large sample sizes, some of the studies involved small patient populations, which could limit the external validity of their results ${ }^{[16,21,25,16,21]}$. Finally, we excluded non-English language studies, and it is possible that in doing so excluded some studies that may have been pertinent to our review.

\section{Disclosures}

Dr. Gehi reports grant support from Bristol-Myers-Squib Foundation and speaker's honoraria from Zoll, Biotronik, and Abbott.

\section{Conclusion}

This systematic review is the first study to our knowledge to evaluate the optimal management of symptomatic AF/AFL in the ED with a direct impact on ED disposition. Based on our findings, there are several viable strategies to employ, all of which may result in a safe ED discharge to home in the right patient population. A suggested general protocol is included in [Figure 2]. The decision aids included in our study can be helpful for determining which patients can be safely managed in the outpatient setting and which require inpatient evaluation. The use of cardioversion in the ED can help expedite discharge, and DCCV has a higher success rate than chemical cardioversion, but conversion to NSR is not a requisite for a safe ED discharge.Early outpatient follow-up is crucial to prevent repeat $\mathrm{ED}$ visits and ensure long-term care.However, future studies of acute $\mathrm{AF} / \mathrm{AFL}$ care are needed to develop management strategies that are comprehensive, in order to determine best practices and demonstrate scalability of systems of care to a variety of settings. 


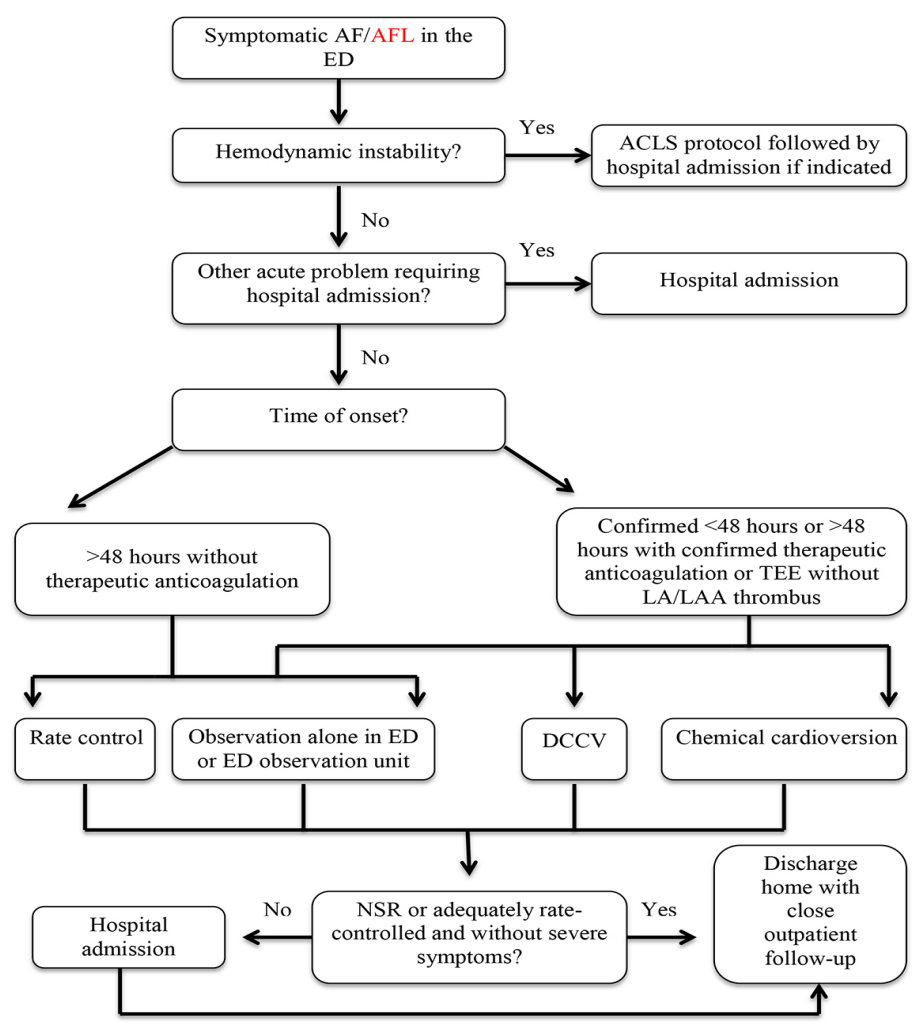

\section{Figure 2: Suggested Protocol for ED Management of AF/AFL}

ACLS = advanced cardiovascular life support, AF $=$ atrial fibrillation, AFL $=$ atrial flutter, DCCV = direct current cardioversion, ED = emergency department, LA/LAA $=$ left atrium/left atrial appendage, NSR $=$ normal sinus rhythm, TEE $=$ transesophageal echocardiogram

\section{References}

1. Go A S, Hylek EM, PhillipsKA, Chang Y, Henault LE, Selby JV, Singer DE. Prevalence of diagnosed atrial fibrillation in adults: national implications for rhythm management and stroke prevention: the AnTicoagulation and Risk Factors in Atrial Fibrillation (ATRIA) Study. JAMA. 2001;285 (18):2370-5.

2. Colilla S, Crow A, Petkun W, Singer DE, Simon T, Liu X. Estimates of current and future incidence and prevalence of atrial fibrillation in the U.S. adult population. Am. J. Cardiol. 2013;112 (8):1142-7.

3. McDonald AJ, Pelletier AJ, Ellinor PT, Camargo CA. Increasing US emergency department visit rates and subsequent hospital admissions for atrial fibrillation from 1993 to 2004. Ann Emerg Med. 2008;51 (1):58-65.

4. Kim MH, Johnston SS, Chu BC, Dalal MR, Schulman KL. Estimation of total incremental health care costs in patients with atrial fibrillation in the United States. Circ Cardiovasc Qual Outcomes. 2011;4 (3):313-20.

5. January CT, Wann LS, Alpert JS, Calkins H, Cigarroa JE, Cleveland JC, Conti JB, Ellinor PT, Ezekowitz MD, Field ME, Murray KT, Sacco RL, Stevenson WG, Tchou PJ, Tracy CM, Yancy CW. 2014 AHA/ACC/HRS guideline for the management of patients with atrial fibrillation: a report of the American College of Cardiology/American Heart Association Task Force on practice guidelines and the Heart Rhythm Society. Circulation. 2014;130 (23):e199-267.

6. Stiell IG, Macle L. Canadian Cardiovascular Society atrial fibrillation guidelines 2010: management of recent-onset atrial fibrillation and flutter in the emergency department. Can J Cardiol. 2011;27 (1):38-46.

7. Mulcahy B, Coates WC, Henneman PL, Lewis RJ. New-onset atrial fibrillation: when is admission medically justified?. Acad Emerg Med. 1996;3 (2):114-19.

8. Barrett TW, Martin AR, Storrow AB, Jenkins CA, Harrell FE, Russ S, Roden DM, Darbar D. A clinical prediction model to estimate risk for 30-day adverse events in emergency department patients with symptomatic atrial fibrillation. Ann Emerg Med. 2011;57 (1):1-12.
9. Atzema CL, Austin PC, Chong AS, Dorian P. Factors associated with 90-day death after emergency department discharge for atrial fibrillation. Ann Emerg Med. 2013;61 (5):539-548.e1.

10. Atzema CL, Dorian P, Ivers NM, Chong AS, Austin PC. Evaluating early repeat emergency department use in patients with atrial fibrillation: a population-based analysis. Am. Heart J. 2013;165 (6):939-48.

11. Barrett TW, Jenkins CA, Self WH. Validation of the Risk Estimator Decision Aid for Atrial Fibrillation (RED-AF) for predicting 30-day adverse events in emergency department patients with atrial fibrillation. Ann Emerg Med. 2015;65 (1):13-21.e3.

12. Barrett TW, Storrow AB, Jenkins CA, Abraham RL, Liu D, Miller KF, Moser KM, Russ S, Roden DM, Harrell FE, Darbar D. The AFFORD clinical decision aid to identify emergency department patients with atrial fibrillation at low risk for 30-day adverse events. Am. J. Cardiol. 2015;115 (6):763-70.

13. Atzema CL, Dorian P, Fang J, Tu JV, Lee DS, Chong AS, Austin PC. A Clinical Decision Instrument for 30-Day Death After an Emergency Department Visit for Atrial Fibrillation: The Atrial Fibrillation in the Emergency Room (AFTER) Study. Ann Emerg Med. 2015;66 (6):658-668.e6.

14. Burton JH, Vinson DR, Drummond K, Strout TD, Thode HC, McInturff JJ. Electrical cardioversion of emergency department patients with atrial fibrillation. Ann Emerg Med. 2004;44 (1):20-30.

15. Jacoby JL, Cesta M, Heller MB, Salen P, Reed J. Synchronized emergency department cardioversion of atrial dysrhythmias saves time, money and resources. J Emerg Med. 2005;28 (1):27-30.

16. Lo GK, Fatovich DM, Haig AD. Biphasic cardioversion of acute atrial fibrillation in the emergency department. Emerg Med J. 2006;23 (1):51-3.

17. Dankner R, Shahar A, Novikov I, Agmon U, Ziv A, Hod H. Treatment of stable atrial fibrillation in the emergency department: a population-based comparison of electrical direct-current versus pharmacological cardioversion or conservative management. Cardiology. 2009;112 (4):270-8.

18. Xavier SF, Grafstein E, Stenstrom R, Innes G, Poures 1, Sighary M. Thirty-day outcomes of emergency department patients undergoing electrical cardioversion for atrial fibrillation or flutter. Acad Emerg Med. 2010;17 (4):408-15.

19. Scheuermeyer FX, Grafstein E, Heilbron B, Innes G. Emergency department management and 1-year outcomes of patients with atrial flutter. Ann Emerg Med. 2011;57 (6):564-571.e2.

20. Cristoni L, Tampieri A, Mucci F, Iannone P, Venturi A, Cavazza M, Lenzi T. Cardioversion of acute atrial fibrillation in the short observation unit: comparison of a protocol focused on electrical cardioversion with simple antiarrhythmic treatment. Emerg Med J. 2011;28 (11):932-7.

21. Innes GD, Vertesi L, Dillon EC, Metcalfe C. Effectiveness of verapamil-quinidine versus digoxin-quinidine in the emergency department treatment of paroxysmal atrial fibrillation. Ann Emerg Med. 1997;29 (1):126-34.

22. Ganau G, Lenzi T. Intravenous propafenone for converting recent onset atrial fibrillation in emergency departments: a randomized placebo-controlled multicenter trial. FAPS Investigators Study Group. J Emerg Med. 1998;16 (3):383-7.

23. Ergene U, Ergene O, Cete Y, Fowler J, Nazli C, Oktay C. Predictors of success in the conversion of new-onset atrial fibrillation using oral propafenone. Eur J Emerg Med. 1998;5 (4):425-8.

24. Domanovits H, Schillinger M, Thoennissen J, Nikfardjam M, Janata K, Brunner M, Laggner AN. Termination of recent-onset atrial fibrillation/flutter in the emergency department: a sequential approach with intravenous ibutilide and external electrical cardioversion. Resuscitation. 2000;45 (3):181-7.

25. Mountantonakis SE, Moutzouris DA, Tiu RV, Papaioannou GN, McPherson CA. Ibutilide to expedite ED therapy for recent-onset atrial fibrillation flutter. Am J Emerg Med. 2006;24 (4):407-12.

26. Viktorsdottir O, Henriksdottir A, Arnar D O. Ibutilide for treatment of atrial 
fibrillation in the emergency department. Emerg Med J. 2006;23 (2):133-4.

27. Stiell IG, Clement CM, Symington C, Perry JJ, Vaillancourt C, Wells GA. Emergency department use of intravenous procainamide for patients with acute atrial fibrillation or flutter. Acad Emerg Med. 2007;14 (12):1158-64.

28. Hirschl MM, Wollmann C, Globits S. A 2-year survey of treatment of acute atrial fibrillation in an ED. Am J Emerg Med. 2011;29 (5):534-40.

29. Scheuermeyer FX Grafstein E, Stenstrom R, Christenson J, Heslop C, Heilbron B, McGrath L, Innes G. Safety and efficiency of calcium channel blockers versus beta-blockers for rate control in patients with atrial fibrillation and no acute underlying medical illness. Acad Emerg Med. 2013;20 (3):222-30.

30. White JL, Heller MB, Kahoud RJ, Slade D, Harding JD. Performance of an expedited rhythm control method for recent onset atrial fibrillation in a community hospital. Am J Emerg Med. 2015;33 (7):957-62.

31. Michael JA, StiellI G, Agarwal S, Mandavia DP. Cardioversion of paroxysmal atrial fibrillation in the emergency department. Ann Emerg Med. 1999;33 (4):379-87.

32. Koenig BO, Ross MA, Jackson RE. An emergency department observation unit protocol for acute-onset atrial fibrillation is feasible. Ann Emerg Med. 2002;39 (4):374-81.

33. Kim MH, Morady F, Conlon B, Kronick S, Lowell M, Bruckman D, Armstrong WF, Eagle KA. A prospective, randomized, controlled trial of an emergency department-based atrial fibrillation treatment strategy with low-molecularweight heparin. Ann Emerg Med. 2002;40 (2):187-92.

34. Zimetbaum P, Reynolds MR, Ho Kalon KL, Gaziano T, McDonald MJ, McClennen S, Berezin R, Josephson ME, Cohen DJ. Impact of a practice guideline for patients with atrial fibrillation on medical resource utilization and costs. Am. J. Cardiol. 2003;92 (6):677-81.

35. Decker WW, Smars PA, Vaidyanathan L, Goyal DG, Boie ET, Stead LG, Packer DL, Meloy TD, Boggust AJ, Haro LH, Laudon DA, Lobl JK, Sadosty AT, Schears RM, Schiebel NE, Hodge DO, Shen WK. A prospective, randomized trial of an emergency department observation unit for acute onset atrial fibrillation. Ann Emerg Med. 2008;52 (4):322-8.

36. Stiell IG, Clement CM, Perry JJ, Vaillancourt C, Symington C, Dickinson G, Birnie D, Green MS. Association of the Ottawa Aggressive Protocol with rapid discharge of emergency department patients with recent-onset atrial fibrillation or flutter. CJEM. 2010;12 (3):181-91.

37. Scheuermeyer FX, Grafstein E, Stenstrom R, Innes G, Heslop C, Mac PJ, Pourvali R, Heilbron B, McGrath L, Christenson J. Thirty-day and 1-year outcomes of emergency department patients with atrial fibrillation and no acute underlying medical cause. Ann Emerg Med. 2012;60 (6):755-765.e2.

38. Vinson DR, Hoehn T, Graber DJ, Williams TM. Managing emergency department patients with recent-onset atrial fibrillation. J Emerg Med. 2012;42 (2):139-48.

39. Elmouchi DA, Van OS, Muthusamy P, Khan M, Puetz C, Davis AT, Brown MD. Impact of an emergency department-initiated clinical protocol for the evaluation and treatment of atrial fibrillation. Crit Pathw Cardiol. 2014;13 (2):43-8.

40. Ptaszek LM, White B, Lubitz SA, Carnicelli AP, Heist EK, Ellinor PT, Machado M, Wasfy JH, Ruskin JN, Armstrong K, Brown DF, Biddinger PD, Mansour M. Effect of a Multidisciplinary Approach for the Management of Patients With Atrial Fibrillation in the Emergency Department on Hospital Admission Rate and Length of Stay. Am. J. Cardiol. 2016;118 (1):64-71. 